\title{
ON THE CONDITION WHICH DETERMINES THE CHEMICAL SIMILARITY OF ELEMENTS AND RADICLES
}

\section{BY GEOFFREY MARTIN}

We propose to show in this paper that chemically similar elements attract the same radicles with proportional intensities of force, whereas chemically unlike elements attract them with unlike intensities. Mathematically this may be expressed thus: If we denote the attractions which an element $A$ exerts on the various radicles $\mathrm{A}, \mathrm{B}, \mathrm{C}, \mathrm{D} \ldots$ by $\jmath_{1}, f_{2}, \jmath_{3}, \ldots f_{n}$; and the corresponding attractions which an element $\mathrm{B}$ exerts by $f^{\prime}{ }_{1}, f^{\prime}{ }_{2}$, $f^{\prime}{ }_{3}, \ldots f^{\prime}{ }_{n}$. Then, if the elements $\mathrm{A}$ and $\mathrm{B}$ are chemically similar, the following relation holds:

$$
\frac{f_{1}}{f_{1}^{\prime}}=\frac{f_{2}}{f_{2}^{\prime}}=\frac{f_{s}}{f_{3}^{\prime}}=\ldots=\frac{f_{n}}{f_{n}^{\prime}}=\mathrm{K}
$$

Further we will show that the closer $\mathrm{K}$ approaches unity, the closer the elements approach each other in their chemical properties. When $\mathrm{K}=\mathrm{I}$ the forces the two elements exert are equal and this is obviously the condition that the elements $A$. and $B$ may be perfectly chemically similar, for in this case one may replace the other in any chemical reaction without altering the nature and direction of the reaction which is determined by these forces.

When $\mathrm{K}=n$ the one element possesses the same chemical properties as the other, but intensified $n$-fold. For example for the system fluorine and chlorine, $\mathrm{K}$ has the value $\mathrm{I} .7$ as the following thermal data shows (see later):

$$
\begin{array}{ll}
\left(\mathrm{F}, \mathrm{Si} \frac{\mathrm{I}}{4}\right)=67.3=f_{1} & \left(\mathrm{Cl}, \mathrm{Si} \frac{\mathrm{I}}{4}\right)=39.4=f_{1}^{\prime} \\
(\mathrm{F}, \mathrm{H})=37.6=f_{2} & (\mathrm{Cl}, \mathrm{H})=22.0=f_{2}^{\prime}
\end{array}
$$

where 


$$
\begin{aligned}
& \frac{f_{1}}{f_{1}^{\prime}}=\frac{67.3}{39.4}=\mathrm{I} .7 \mathrm{I} \\
& \frac{f_{2}}{f_{2}}=\frac{39.4}{22.0}=\mathrm{I} .70 .
\end{aligned}
$$

This means that fluorine possesses the same chemical properties as chlorine, but intensified r.7-fold.

In general, the relationship ( $\mathrm{I}$ ) is not satisfied by the affinities of any two elements $\mathrm{A}$ and $\mathrm{B}$ selected at random. We find, however, that the more closely their affinities conform to this law, the closer is their chemical resemblance. And conversely, the more widely their affinities depart from this law, the remoter is their chemical resemblance, so that in the case of elements which behave in a quite different way chemically, this relation ship is not even remotely satisfied, as we will presently show.

No two elements are perfectly chemically similar. All exhibit certain chemical peculiarities which distinguish one from the other. Therefore the relation (I) is never exactly satisfied by the affinities of two elements, but is the limiting condition which is more and more exactly fulfilled as the elements approach more and more exactly to perfect chemical similarity. For atoms of the same element alone is the condition exactly fulfilled, $\mathrm{K}$ here taking the value unity since the forces are now of the same intensity.

It may be noted that many of the so-called radicles play the part of elementary atoms, although quite incapable of existing separately (for example $\mathrm{NH}_{4}-,-\mathrm{N}_{3},-\mathrm{CN}$ ), simply because they are arrangements of atoms so combined together as to exert forces of the same intensity as the elementary atoms, of which they play the part.

The best way to make the above law evident, is to contrast the quantities of heat evolved when equivalent quantities of like and unlike elements combine with the same radicles. Of course, it must be remembered that the heat evolved in the formation of a compound, does not exactly measure the force driving the atoms together, except perhaps, at the absolute zero of temperature. Further, the heats of formation of compounds as given in 
the text-books are not the true heats of formation, but are merely difference effects which may be positive or negative-where the true heats of formation must be always positive. For example, when hydrogen combines with iodine, the change is not simply

$$
\mathrm{H}+\mathrm{I}=\mathrm{HI}
$$

but is a double decomposition; thus :

$$
\left.\left.\left.\left.\begin{array}{l}
\mathrm{H} \\
\mathrm{H}
\end{array}\right\}+\begin{array}{l}
\mathrm{I} \\
\mathrm{I}
\end{array}\right\}=\begin{array}{c}
\mathrm{H} \\
\mathrm{I}
\end{array}\right\}+\begin{array}{c}
\mathrm{H} \\
\mathrm{I}
\end{array}\right\} .
$$

Now, if the heat required to effect the separation of $\mathrm{H}$ from $\mathrm{H}$, and $I$ from $I$, is greater than the amount of heat generated when $2 \mathrm{H}$ combines with $2 \mathrm{I}$, then the result will be negative.

Hence it is apparent that even in those cases of chemical action in which an evolution of heat is actually observed, this heat represents only the surplus energy remaining over after the breaking up of the molecules of the original substances employed in the experiment. In fact it is only when the heat evolved in the formation of a compound is very great, that it can be taken as measuring approximately the attractive forces, for in this case the incidental errors become small in comparison with the quantity of heat evolved. Bearing these limitations in mind, the conformance to the above law which appears (as we will immediately show) when we contrast the quantities I have evolved when the atoms of chemically similar elements unite with the same radicle, must be regarded as nothing else than surprising.

\section{Chemically Unlike Elements}

When we contrast chemically unlike elements the relations

$$
\frac{f_{1}}{f_{1}^{\prime}}=\frac{f_{2}}{f_{2}^{\prime}}=\frac{f_{3}}{f_{s}^{\prime}}=\ldots \ldots=\frac{f_{n}}{\tilde{f}_{n}^{\prime}}=\mathrm{K}
$$

are not even remotely satisfied, and $\mathrm{K}$ varies widely and irregularly for every different ratio.

As typical pairs of unlike elements, we will contrast $\mathrm{H}$ with $\mathrm{Cl}$, on the one hand, $\mathrm{O}$ with $\mathrm{I}$ on the other. In neither case are the relations satisfied. 


\section{Hydrogen and Chlorine}

\begin{tabular}{|c|c|c|c|c|c|}
\hline$(\mathrm{H}, \mathrm{Li})=$ & 21.6 & $=f_{1}^{\prime}$ & $(\mathrm{Cl}, \mathrm{Li})=$ & 94 & \\
\hline$(\mathrm{H}, \mathrm{Na})=$ & 13 & $=f_{2}^{\prime}$ & $(\mathrm{Cl}, \mathrm{Na})=$ & 98 & \\
\hline$\left(\mathrm{H}, \mathrm{C}^{2} / 4\right)=$ & 5.4 & $=f_{3}{ }^{\prime}$ & $\left(\mathrm{Cl}, \mathrm{C}^{1} / 4\right)=$ & 13.5 & \\
\hline$\left(\mathrm{H}, \mathrm{Si}^{1} / 4\right)=$ & 8.2 & $=f_{4}^{\prime}$ & $\left(\mathrm{Cl}, \mathrm{Si}^{\mathrm{i}} /{ }_{4}\right)=$ & 39 & \\
\hline$\left(\mathrm{H}, \mathrm{N}^{1} / 8\right)=$ & 4.0 & $=f_{5}^{\prime}$ & $\left(\mathrm{Cl}, \mathrm{N}^{1} / 3\right)=$ & -13 & \\
\hline$\left(\mathrm{H}, \mathrm{P}^{1 / 3}\right)=$ & 3.86 & $=\dot{f}_{6}^{\prime}$ & $\left(\mathrm{Cl}, \mathrm{P}^{1 / 3}\right)=$ & 25 & \\
\hline$\left(\mathrm{H}, \mathrm{As}_{1 / 9}^{1}\right)=$ & -12.2 & $=f_{i}^{\prime}$ & $\left(\mathrm{Cl}, \mathrm{As}^{1 / 8}\right)=$ & 24 & \\
\hline $1 / 3)=-$ & -28.1 & $=f_{8}^{\prime}$ & $\left(\mathrm{Cl}, \mathrm{Sb}_{3} / 3\right)=$ & 30.46 & \\
\hline ) $=$ & 34.2 & $=f_{9}^{\prime}$ & $\left(\mathrm{Cl}, \mathrm{O}^{1} / 2\right)=$ & -9. & \\
\hline 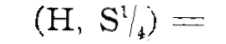 & 2.3 & $=f_{10}$ & $\left(\mathrm{Cl}, \mathrm{S}^{1} / 4\right)=$ & 6 & \\
\hline
\end{tabular}

Whence

$$
\begin{array}{ll}
\frac{f_{1}}{\tilde{f}_{1}^{\prime}}=\frac{94}{21.6}=4.3 & \frac{f_{6}}{f_{6}^{\prime}}=\frac{25}{3.86}=6.5 \\
\frac{f_{2}}{\bar{f}_{2}^{\prime}}=\frac{98}{\mathrm{I} 3}=7.5 & \frac{f_{7}}{\tilde{f}_{7}^{\prime}}=\frac{24}{-12.2}=-\mathrm{I} .9 \\
\frac{f_{3}}{f_{3}^{\prime}}=\frac{13.5}{5.4}=2.3 & f_{8}=\frac{30.46}{-28.1}=-\mathrm{I} \\
f_{4}^{\prime}=\frac{39}{f_{8}^{\prime}}=4.7 & \frac{f_{9}}{f_{9}^{\prime}}=\frac{-9}{34.2}=-0.26 \\
f_{4}^{\prime}=8.2 & \frac{f_{10}}{f_{5}^{\prime}}=\frac{6}{2.3}=-13=2.6
\end{array}
$$

Hence $\mathrm{K}$ takes in succession each of the following values: $4.3,7.5,2.3,4.7,-3.2,5.5,-\mathrm{I} .9,-\mathrm{I},-0.26,2.6$.

The ratio is in no case constant but varies widely and irregularly. The varying of $\mathrm{K}$ would be very much greater if we only knew the H.F. of all the corresponding compounds; but as a matter of fact experimental difficulties limit the determination of the H.F. of compounds only to those which are stable enough to exist at an ordinary temperature. Many compounds of chlorine are known of great stability, whereas the corresponding hydrides are too unstable to exist at ordinary temperatures, e.g., $\mathrm{PbCl}_{2}$ and $\mathrm{PbH}_{2}$. 


\section{Iodine and Oxygen}

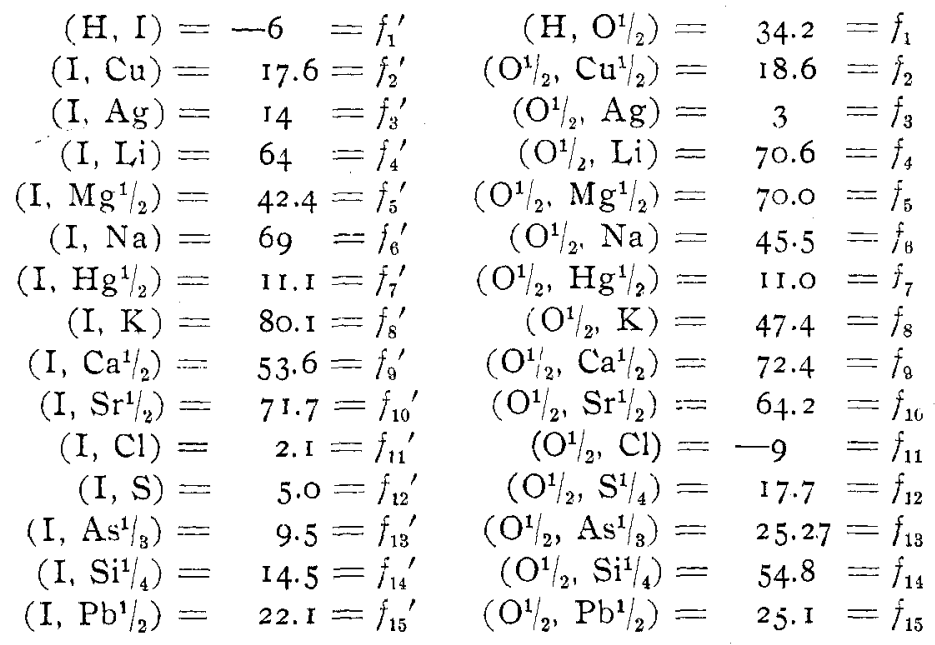

Whence

$$
\begin{aligned}
& \frac{f_{1}}{f_{1}^{\prime}}=\frac{34.2}{-6}=-5.7 \\
& \frac{f_{8}}{f_{8}^{\prime}}=\frac{47.4}{80.1}=0.59 \\
& \frac{f_{2}}{f_{2}^{\prime}}=\frac{18.6}{17.6}=1.06 \\
& \frac{f_{9}}{f_{9}^{\prime}}=\frac{72.4}{53.6}=\mathrm{x} .35 \\
& \frac{f_{3}}{f_{3}^{\prime}}=\frac{3}{14}=0.21 \\
& \frac{f_{10}}{f_{10}}=\frac{64.2}{7 \mathrm{~T} .7}=0.89 \\
& \frac{f_{4}}{i_{4}^{\prime}}=\frac{70.6}{64}=\mathrm{I}, 10 \\
& \frac{f_{11}}{f_{11}}=\frac{-9}{2 . I}=-4.3 \\
& \frac{f_{5}}{f_{5}^{\prime}}=\frac{70.0}{42.4}=\mathrm{I} .65 \\
& f_{12},=\frac{17.7}{5.0}=3.54 \\
& \frac{f_{\theta}}{f_{\theta}{ }^{\prime}}=\frac{45.5}{69}=0.66 \\
& \frac{f_{13}}{f_{13}}=\frac{25.77}{9.5}=2.7 \\
& \frac{f_{7}}{f_{7}^{\prime}}=\frac{\text { II }}{\text { II. I }}=0.99 \\
& \frac{f_{14}}{f_{14}}=-\frac{54.8}{14.5}=3.78 \\
& \frac{f_{15}}{f_{15}}=\frac{25.1}{22.1}=\text { I.I } 4
\end{aligned}
$$

$\mathrm{K}$, therefore, takes any of the following values: -5.7 , I.06, 0.2 I, I.IO, I.65, $0.66,0.99,0.59$, I.35, $0.89,-4.3,3.54,2.7$, 3.78 , I.I 4 , and hence is not even remotely constant.

An examination of the corresponding compounds of any two dissimilar elements will reveal the same peculiarity. 


\section{Chemically Similar Elements}

When, however, we contrast chemically similar elements, a very different relationship is observed. $\mathrm{K}$ remains approximately constant.

\section{Chlorine and Bromine}

\begin{tabular}{|c|c|c|c|c|}
\hline$(\mathrm{Cl}, \mathrm{Cu})=$ & 32.9 & $=\dot{f}_{1}$ & $(\mathrm{Br}, \mathrm{Cu})=25$ & $=f_{1}^{\prime}$ \\
\hline$(\mathrm{Cl}, \mathrm{Ag})=$ & 29.2 & $=f_{2}$ & $(\mathrm{Br}, \mathrm{Ag})=22.7$ & $=1$ \\
\hline$(\mathrm{Cl}, \mathrm{Li})=$ & 93.8 & $=f_{3}$ & $(\mathrm{Br}, \mathrm{Li})=80$ & \\
\hline$(\mathrm{Cl}, \mathrm{Na})=$ & 97.7 & $==f_{4}$ & $(\mathrm{Br}, \mathrm{Na})=85.8$ & \\
\hline$(\mathrm{Cl}, \mathrm{K})=$ & 105.6 & $=f_{5}$ & $(\mathrm{Br}, \mathrm{K})=95.3$ & \\
\hline$\left(\mathrm{Cl}, \mathrm{Ca}^{1} / 2\right)=$ & 84.6 & $=\hat{f}_{\mathrm{B}}$ & $\left(\mathrm{Br}, \mathrm{Ca}^{1} / 2\right)=70.4$ & \\
\hline$\left(\mathrm{Cl}, \mathrm{Sr}^{1 / 2}\right)=$ & 92.3 & $=f_{i}$ & $\left(\mathrm{Br}, \mathrm{Sr}^{1} / 2\right)=78.8$ & \\
\hline$\left(\mathrm{Cl}, \mathrm{Ba}^{1}{ }_{2}\right)=$ & $97 \cdot 3$ & $=:=f_{8}$ & $\left(\mathrm{Br}, \mathrm{Ba}^{1} / 2\right)=85.0$ & \\
\hline$\left(\mathrm{Cl}, \mathrm{Zn}^{1} / 2\right)=$ & 48.6 & $=f_{\theta}$ & $\left(\mathrm{Br}, \mathrm{Zn}^{1} / 2\right)=40.0$ & \\
\hline$\left(\mathrm{Cl}, \mathrm{Hg}^{1 / 2}\right)=$ & 27.2 & $=f_{10}$ & $\left(\mathrm{Br}, \mathrm{Hg}^{1} / 2\right)=20.3$ & \\
\hline$(\mathrm{Hg}, \mathrm{Cl})=$ & 32.6 & & $(\mathrm{Br}, \mathrm{Hg})=24.5$ & \\
\hline$\left(\mathrm{Cl}, \mathrm{Al}^{1 / 3}\right)=$ & 53.66 & $b=f_{12}$ & $\left(\mathrm{Br}, \mathrm{Al}^{1} / 3\right)=41.0$ & \\
\hline$\left(\mathrm{Cl}, \mathrm{As}^{1 / 3}\right)=$ & 23.8 & & $\left(\mathrm{Br}, \mathrm{As}^{1 / 3}\right)=19.7$ & \\
\hline$\left(\mathrm{Cl}, \mathrm{Sb}^{1} / 3\right)=$ & 30.46 & $=f_{14}$ & $\left(\mathrm{Br}, \mathrm{Sb}^{1 / 3}\right)=25.6$ & \\
\hline$\left(\mathrm{Cl}, \mathrm{Pb}^{1} / 2\right)=$ & $4^{1.0}$ & & $\left(\mathrm{Br}, \mathrm{Pb}^{1 / 2}\right)=36.0$ & \\
\hline
\end{tabular}

Whence

$$
\begin{aligned}
& f_{1}=\frac{.32 .9}{25}=\mathrm{I} .32 \\
& \frac{f_{8}}{\bar{f}_{8}^{\prime}}=\frac{97.3}{85.0}=1.15 \\
& \frac{f_{2}}{f_{2}^{\prime}}=\frac{29.2}{22.7}=\mathrm{I} .29 \\
& \frac{f_{9}}{\hat{f}_{9}^{\prime}}=\frac{48.6}{40.0}=\mathrm{I} .2 \mathrm{I} \\
& f_{3}{ }_{f_{3}}{ }^{\prime}=\frac{93.8}{80}=1.17 \\
& \frac{f_{10}}{f_{10}},=\frac{27.2}{20.3}=\mathbf{I} .34 \\
& \frac{f_{4}}{f_{4}^{\prime}}=\frac{97.7}{85.8}=\mathrm{I} .14 \\
& \frac{f_{11}}{f_{11}}=\frac{32.6}{24.5}=\mathrm{I} .33 \\
& \frac{f_{5}}{f_{\varepsilon}^{\prime}}=\frac{105.6}{95.3}=\mathrm{I} . \mathrm{II} \\
& {\frac{f_{12}}{f_{12}}}^{\prime}=\frac{53.66}{7 \mathrm{I} .0}=\mathrm{I} \cdot 3 \mathrm{O} \\
& \frac{f_{6}}{f_{6}^{\prime}}=\frac{84.6}{70.4}=1.20 \\
& \frac{f_{13}}{f_{13}},=\frac{23.8}{19.7}=1.21 \\
& \frac{f_{7}}{f_{7}^{\prime}}=\frac{92.3}{78.8}=\mathrm{I} \cdot \mathrm{I} 8 \\
& \frac{f_{14}}{f_{14}^{\prime}},=\frac{30.46}{25.63}=1.19 \\
& \frac{f_{15}}{\bar{f}_{15}^{\prime}}=\frac{4 \mathrm{I}}{3^{6}}=\mathrm{I} . \mathrm{I} 4
\end{aligned}
$$


$\mathrm{K}$ is here throughout the series approximately constant, never becoming greater than I.34 nor less than I.II.

When we contrast these values of $\mathrm{K}$ with the previous values, we see how closely constant $\mathrm{K}$ remains. The values of $\mathrm{K}$ range in the case of $\mathrm{H}$ and $\mathrm{Cl}$ from 7.5 to -3.2 and in the case of $\mathrm{O}$ and $\mathrm{I}$, from -5.7 to $3.7^{8}$.

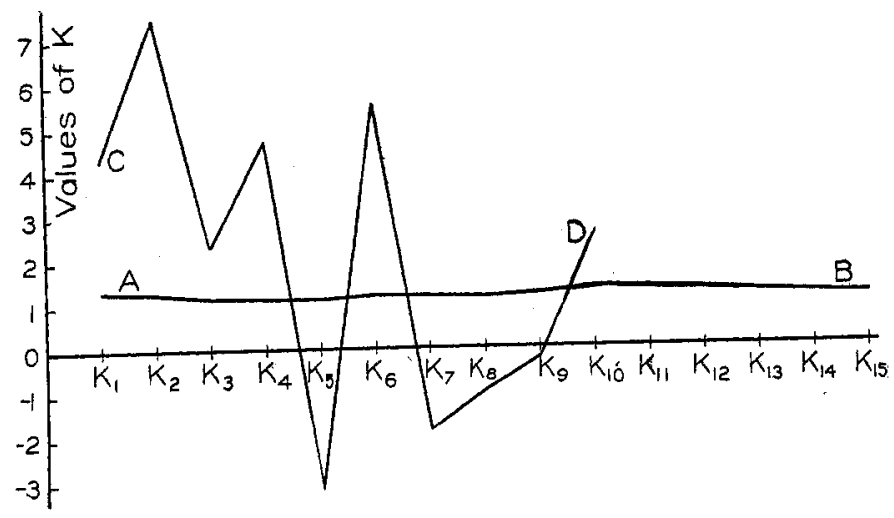

Fig. I

Showing the approximate constancy of $\mathrm{K}$ for similar elements $(\mathrm{Cl}$ and $\mathrm{Br}$ ) and its variation for dissimilar elements $(\mathrm{Cl}$ and $\mathrm{H})$.

The erratic line $\mathrm{CD}$ records the successive values of $\mathrm{K}$ for the system $\mathrm{Cl}$ and $H$. The nearly straight line $A B$ records the successive values of $K$ for the system $\mathrm{Cl}$ and $\mathrm{Br}$.

The approximate constancy of $\mathrm{K}$ for similar elements, and its variation for dissimilar elements is best demonstrated graphically. Writing $\mathrm{K}_{1}$ for $\frac{f_{1}}{f_{1}^{\prime}} ; \mathrm{K}_{2}$ for $\frac{f_{2}}{f_{2}^{\prime}} ; \ldots \ldots \mathrm{K}_{n}$ for $\frac{f_{n}}{f_{n}} ;$; and taking $\mathrm{K}_{1}, \mathrm{~K}_{2}, \mathrm{~K}_{3}, \mathrm{~K}_{4} \ldots \ldots \mathrm{K}_{n}$ as abcissae, and the successive numerical values as ordinates, we find for the system $\mathrm{Cl}$ and $\mathrm{H}$ an erratic line, for the system $\mathrm{Cl}$ and $\mathrm{Br}$ an almost straight line parallel to the axis of $x$ (Fig. I).

\section{Fluorine and Chlorine}

The only data available is the following:

$$
\begin{aligned}
\left(\mathrm{F}, \mathrm{Si}^{1} l_{4}\right) & =67.3=f_{1} & \left(\mathrm{Cl}, \mathrm{Si}^{1}{ }_{4}\right) & =39.4=f_{1}^{\prime} \\
(\mathrm{F}, \mathrm{H}) & =37.6=f_{2} & (\mathrm{Cl}, \mathrm{H}) & =22=f_{2}^{\prime}
\end{aligned}
$$


Whence :

$$
\begin{aligned}
& \frac{f_{1}}{f_{1}^{\prime}}=\frac{67.3}{39.4}=1.7 \mathrm{I} \\
& \frac{f_{2}}{f_{2}{ }^{\prime}}=\frac{37.6}{22}=1.70
\end{aligned}
$$

The ratio is, therefore, constant even for such different elements as $\mathrm{H}$ and $\mathrm{Si}$.

The large value of $\mathrm{K}$ shows, that $\mathrm{F}$ possesses the same chemical properties as $\mathrm{Cl}$, but intensified I.70 times.

\section{Sodium and Potassium}

The only data available is the following:

$$
\begin{aligned}
(\mathrm{K}, \mathrm{Cl}) & =105.6=f_{1} & (\mathrm{Na}, \mathrm{Cl}) & =97.7=f_{1}^{\prime} \\
(\mathrm{K}, \mathrm{Br}) & =95.3=f_{2} & (\mathrm{Na}, \mathrm{Br}) & =85.8=f_{2}^{\prime} \\
(\mathrm{K}, \mathrm{I}) & =80 . \mathrm{I}=f_{8} & (\mathrm{Na}, \mathrm{I}) & =69.1=f_{3}^{\prime} \\
\left(\mathrm{K}, \mathrm{O}^{1} / 2\right) & =47.4=f_{4} & \left(\mathrm{Na}, \mathrm{O}_{2}\right) & =45.5=f_{4}^{\prime} \\
\left(\mathrm{K}, \mathrm{NH}_{3}\right) & =6.3=f_{5} & \left(\mathrm{Na}, \mathrm{NH}_{3}\right) & =5.2=f_{5}^{\prime}
\end{aligned}
$$

Whence :

$$
\begin{aligned}
& \frac{f_{1}}{f_{1}^{\prime}}=\frac{\text { I05.6 }}{97.7}=\mathrm{I} .08 \quad \frac{f_{3}}{f_{3}{ }^{\prime}}=\frac{80 . \mathrm{I}}{69 . \mathrm{I}}=\mathrm{I} . \mathrm{I} 6 \\
& \frac{f_{2}}{f_{2}^{\prime}}=\frac{95.3}{85.8}=\text { I.I I. } \quad \frac{f_{4}}{f_{4}^{\prime}}=\frac{47.4}{45.5}=1.05 \\
& \frac{f_{5}}{f_{5}^{\prime}}=\frac{6.3}{5.2}=\mathrm{I} .2 \mathrm{I}
\end{aligned}
$$

It will be seen, that here also $\mathrm{K}$ is constant and very nearly equal to unity - fact, which explains the great chemical resemblance of $\mathrm{Na}$ and $\mathrm{K}$.

\section{Potassium and Caesium}

The only available data is the following:

$$
\begin{aligned}
(\mathrm{K}, \mathrm{Br}) & =95.3=f_{1}^{\prime} & (\mathrm{Cs}, \mathrm{Br}) & =99.8=f_{1} \\
(\mathrm{~K}, \mathrm{I}) & =80 . \mathrm{r}=f_{2}^{\prime} & (\mathrm{Cs}, \mathrm{I}) & =86.6=f_{2}
\end{aligned}
$$

Whence:

$$
\begin{aligned}
& \frac{f_{1}}{f_{1}^{\prime}}=\frac{99.8}{95.3}=\mathrm{I} .05 \\
& \frac{f_{2}}{\bar{f}_{2}^{\prime}}=\frac{86.6}{80 . \mathrm{I}}=\mathrm{I} .08
\end{aligned}
$$


Here again, $\mathrm{K}$ is constant and very nearly equal to unity. In the case of all the alkali metals this is so, and this is the reason why there exists such a close resemblance between them.

\section{Zine and Cadmium}

The only data available is the following:

$$
\begin{aligned}
\left(\mathrm{Zn}, \mathrm{Cl}_{2}\right) & =97.2=f_{1} & \left(\mathrm{Cd}, \mathrm{Cl}_{2}\right) & =93.0=f_{1}^{\prime} \\
(\mathrm{Zn}, \mathrm{O}) & =85.4=f_{2} & (\mathrm{Cd}, \mathrm{O}) & =75.5=f_{2}{ }^{\prime}
\end{aligned}
$$

Whence :

$$
\begin{aligned}
& \frac{f_{1}}{f_{1}^{\prime}}=\frac{97.2}{93}==\mathrm{I} .04 \\
& \frac{f_{2}}{f_{2}^{\prime}}=\frac{85.4}{75.4}=\mathrm{I} .13
\end{aligned}
$$

Here again $\mathrm{K}$ is constant and nearly equal to unity, which accounts for the close resemblance of $\mathrm{Zn}$ and $\mathrm{Cd}$.

\section{Boron and Silicon}

The case is of great interest, inasmuch as $\mathrm{B}$ and $\mathrm{Si}$ possess a great degree of chemical similarity, and yet $B$ is trivalent and Si tetravalent. The chemical similarity of elements does not, in fact, depend upon their valence but solely upon their attractive forces.

The following data-the only available-shows, that $\mathrm{K}$ is nearly equal to unity, a fact which explains the remarkable chemical resemblance of these two elements.

$$
\begin{aligned}
\left(\mathrm{B}^{1 / 5}, \mathrm{Cl}\right) & =34 \cdot 70=f_{1}^{\prime} \quad\left(\mathrm{Si}^{1}{ }_{4}, \mathrm{C} 1\right)=39.4=f_{1} \\
\left(\mathrm{~B}^{1 / 3}, \mathrm{O}^{1 / 2}\right) & =52.8=f_{2}^{\prime} \quad\left(\mathrm{Si}^{1} /_{4}, \mathrm{O}^{1 / 2}\right)=54.8=f_{2}
\end{aligned}
$$

Hence :

$$
\begin{aligned}
& \frac{f_{1}}{f_{1}^{\prime}}=\frac{39.4}{34.7}=\mathrm{I} . \mathrm{I} 3 \\
& \frac{f_{2}}{f_{2}{ }^{\prime}}=\frac{54.8}{52.8}=\mathrm{r} .04 \\
& \left(\mathrm{Ca}^{1} / 2, \mathrm{Cl}\right)=84.6=f_{1}^{\prime} \quad\left(\operatorname{Sr}^{1} / 2, \mathrm{Cl}\right)=92.3=f_{1} \\
& \left(\mathrm{Ca}^{1}{ }_{2}, \mathrm{Br}\right)=70.4=f_{2}^{\prime} \quad\left(\mathrm{Sr}^{1} / 2, \mathrm{Br}\right)=78.8=f_{2} \\
& \left(\mathrm{Ca}^{1 / 2}, \mathrm{I}\right)=53.6=f_{3}^{\prime} \quad\left(\mathrm{Sr}^{1 /} / 2, \mathrm{I}\right)=7 \mathrm{I} .7=f_{3} \\
& \left(\mathrm{Ca}^{1} / 2, \mathrm{O}^{1} / 2\right)=65.5=f_{4}^{\prime} \quad\left(\mathrm{Sr}^{1}{ }_{2}^{1}, \mathrm{O}^{1 / 2}\right)=64.2=f_{4} \\
& { }^{1} /{ }_{4}\left(\mathrm{Ca}, \mathrm{O}^{2}\right)=37.6=f_{5}{ }^{\prime} \quad{ }_{1 / 4}\left(\mathrm{Sr}, \mathrm{O}^{2}\right)=35.5=f_{5}
\end{aligned}
$$


Whence:

$$
\begin{aligned}
& \frac{f_{1}}{\bar{f}_{1}^{\prime}}=\frac{92.3}{84.6}=\mathrm{I} .09 \quad \frac{f_{3}}{f_{3}^{\prime}}=\frac{71.7}{53.6}=\mathrm{I} .33
\end{aligned}
$$

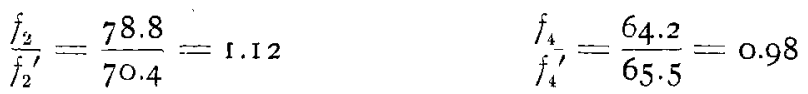

$$
\begin{aligned}
& \frac{f_{5}}{f_{5}^{\prime}}=\frac{35.5}{37.6}=0.94
\end{aligned}
$$

Here again $\mathrm{K}$ is nearly equal to unity, a fact which explains the chemical resemblance of $\mathrm{Ca}$ and $\mathrm{Sr}$.

\section{Strontium and Barium}

$$
\begin{aligned}
& \left(\mathrm{Sr}^{1} /_{2}, \mathrm{Cl}\right)=92.3=f_{1}{ }^{\prime} \\
& \left(\mathrm{Sr}^{1} / 2, \mathrm{Br}\right)=78.8=f_{2}^{\prime} \\
& \left(\mathrm{Ba}^{1} / 2, \mathrm{Cl}\right)=97.3=f_{1} \\
& \left(\mathrm{Sr}^{1} / 2, \mathrm{I}\right)=7 \mathrm{I} .7=f_{3}{ }^{\prime} \\
& \left(\mathrm{Ba}^{2} / 2, \mathrm{Br}\right)=85.0=f_{2} \\
& \left(\mathrm{Ba}^{3} / 2, \mathrm{I}\right)=72.3=f_{3} \\
& \left(\mathrm{Sr}^{1} / 2, \mathrm{O}^{1} / 2\right)=64.2=f_{4}^{\prime} \\
& 1 /{ }_{4}\left(\mathrm{Sr}, \mathrm{O}_{2}\right)=35.5=f_{5}^{\prime} \\
& \left(\mathrm{Ba}^{1} /_{2}, \mathrm{O}^{1} /_{2}\right)=62 . \mathrm{I}=f_{4} \\
& { }^{1} /{ }_{4}\left(\mathrm{Ba}, \mathrm{O}_{2}\right)=34.0=f_{5}
\end{aligned}
$$

Whence:

$$
\begin{array}{ll}
\frac{f_{1}}{f_{1}^{\prime}}=\frac{97.3}{92.3}=1.05 & \frac{f_{3}}{f_{3}^{\prime}}=\frac{72.3}{71.7}=1.01 \\
\frac{f_{2}}{f_{2}^{\prime}}=\frac{85.0}{78.8}=1.08 & \frac{f_{4}}{f_{4}^{\prime}}=\frac{62.1}{64.2}=0.97 \\
\frac{f_{5}}{f_{5}^{\prime}}=\frac{34.0}{35.5}=0.96 &
\end{array}
$$

Here again $\mathrm{K}$ is nearly equal to unity, which accounts for the great chemical similarity of $\mathrm{Sr}$ and $\mathrm{Ba}$.

\section{Nickel and Cobalt}

The only available data is the following:

$$
\begin{aligned}
\left(\mathrm{Ni}^{1} /{ }_{2}, \mathrm{Cl}\right) & =37.2=f_{1}^{\prime} & \left(\mathrm{Co}^{1} / 2, \mathrm{Cl}\right) & =38.2=f_{1} \\
\left(\mathrm{Ni}^{1} / 2, \mathrm{Se}^{1} / /_{2}\right) & =9.2 \mathrm{I}=f_{2}^{\prime} & \left(\mathrm{Co}^{1} / 2, \mathrm{Se}^{1} / 2\right) & =9.64=f_{2} \\
\left(\mathrm{Ni}^{1} /{ }_{2}, \mathrm{Te}^{1} / 2\right) & =7.55=f_{3}^{\prime} & \left(\mathrm{Co}^{1} /_{2}, \mathrm{Te}^{1} / 2\right) & =7.65=f_{3}
\end{aligned}
$$


Whence :

$$
\begin{aligned}
& \frac{f_{1}}{f_{1}^{\prime}}=\frac{38.2}{37.2}=1.02 \\
& \frac{f_{2}}{f_{2}^{\prime}}=\frac{9.64}{9.2 \mathrm{I}}=\mathrm{I} .05 \\
& \frac{f_{3}}{f_{3}^{\prime}}=\frac{7.65}{7.55}=\mathrm{I} .0 \mathrm{I}
\end{aligned}
$$

Here again $K$ is constant and very nearly equal to unity, as we should expected from the remarkable chemical resemblance of $\mathrm{Co}$ to $\mathrm{Ni}$.

\section{Antimony ànd Bismuth}

The data available is meagre:

$$
\begin{aligned}
& \left(\mathrm{Sb}^{1 / 3}, \mathrm{Cl}\right)=30.46=f_{1} \\
& \left(\mathrm{Bi}^{1} /{ }_{3}, \mathrm{Cl}\right)=30.2 \mathrm{I}=f_{1}^{\prime} \\
& \left(\mathrm{Sb}^{2}, \mathrm{O}^{3}, 3 \mathrm{H}_{2} \mathrm{O}\right)=167.5^{2}=f_{2} \\
& \left(\mathrm{Bi}^{2}, \mathrm{O}^{3},{ }_{3} \mathrm{H}_{2} \mathrm{O}\right)=\mathrm{I} 37.74=f_{2}^{\prime}
\end{aligned}
$$

Whence:

$$
\begin{aligned}
& \frac{f_{2}}{f_{1}^{\prime}}=\frac{30.46}{30.21}=\mathrm{I} .0 \mathrm{I} \\
& \frac{f_{2}}{f_{2}^{\prime}}=\frac{167.4}{\mathrm{I} 37.4}=\mathrm{I} .2 \mathrm{I}
\end{aligned}
$$

The preceding pages contain practically all the available thermal data for comparing the corresponding compounds of chemically similar elements. In every case where elements possess a great degree of similarity, $\mathrm{K}$ is approximately constant, and very often nearly unity. And in every case where elements differ widely in their chemical properties, precisely the reserye holds true.

University of Kiel. 